\title{
CDISC SDTM Coronary Artery Disease Risk Terminology
}

National Cancer Institute

\section{Source}

National Cancer Institute. CDISC SDTM Coronary Artery Disease Risk Terminology. NCI Thesaurus. Code C101849.

Terminology associated with the coronary artery disease risk codelist of the Clinical Data Interchange Standards Consortium (CDISC) Study Data T abulation Model (SDT M). 